\title{
Contacts / 1978: Research on Gold in Electrical Contacts
}

\author{
A REVIEW OF THE INTERNATIONAL AND HOLM CONFERENCE ON \\ ELECTRICAL CONTACTS
}

Morton Antler

Bell Laboratories, Columbus, Ohio, U.S.A.

\begin{abstract}
The Ninth International Conference on Electrical Contact Phenomena met jointly with the 24th Annual Holm Conference on Electrical Contacts in Chicago on September 11th to 15th, 1978. Many papers dealing with the uses of gold as a contact material were presented. This review summarizes significant new work in this area.
\end{abstract}

A central theme of the 1978 Conference was the effect of environment on the behaviour of electrical contacts. The nobility of gold has long made it a favourite material for separable electronic connectors, light-duty switches, instrument slip-rings and other components. Nevertheless, thin gold coatings on contact surfaces may be porous and render the substrate susceptible to attack in polluted atmospheres. Tarnish films can form at pore sites on silver and certain base metal substrates. Films may also spread on gold from unplated base metals which are in contact with it and cause electrical resistance to increase. Other coatings on contact surfaces are also subject to these degradation mechanisms.

\section{Creep of Tarnish Films}

W. H. Abbott of Battelle Institute, Columbus, Ohio, examined the kinetics of film creep on electroplated gold having a sharp line of demarcation to bare silver, copper and nickel substrates in an atmosphere of $100 \mathrm{ppb}$ of sulphur dioxide plus $6 \mathrm{ppb}$ of sulphur vapour at $30^{\circ} \mathrm{C}$ and 90 percent relative humidity (R.H.). Creep rates were substantially less from copper than from silver; there was virtually no movement of tarnish films from nickel. Creep distances ranged from about 0.03 to $1 \mathrm{~mm}$ in 1000 hours. A significant finding was that creep rates differed according to the composition (weight per cent) of gold electrodeposit, the ranking being:

gold $/ 0.1$ cobalt $>$ gold $/ 0.1$ nickel $\gg$ gold $/ 1$ indium.
Creep was also more rapid along scratches than on smooth surfaces. Films consisted mainly of sulphide from silver and oxides with a small amount of sulphide from copper. Similar results were observed at pores in gold coatings. Contact resistance determinations suggest that creep was inhibited on the gold-indium coating.

V. Tierney of Bell Laboratories, Murray Hill, New Jersey, reported that films growing on bare copper exposed to sulphiding environments often do not spread on gold electrodeposits. Conditions of exposure of the samples prior to the introduction of sulphur in their environment appeared to play a role; natural oxides that grew on copper inhibited subsequent sulphide formation and creep. Thermally produced oxides offered the same protection as natural oxides. The distance of tarnish creep was also humiditydependent, maximum distances in an atmosphere of flowers of sulphur at $50^{\circ} \mathrm{C}$ being $1.1 \mathrm{~mm}$ at 75 per cent R.H. and $0.62 \mathrm{~mm}$ at 17 per cent R.H. Another finding was that copper sulphide tarnish films were banded. Scanning electron microscope examination showed the borders to be narrow rows of vertical growth of the tarnish rising above the horizontal growth that formed the main body of the film. Creep always progressed through the addition of new bands rather than from broadening of already formed bands.

When the environment is not aggressive to base metal exposed through worn gold coatings, the corrosion films which form are relatively thin and may not spread. G. J. Russ and R. J. Chesseri of Bell Laboratories, Murray Hill, New Jersey, submitted scratched electrodeposited gold coatings of various thicknesses on copper or nickel-plated copper substrates to dry air at $150^{\circ} \mathrm{C}$ for 24 hours, to air at 90 per cent R.H. and $40^{\circ} \mathrm{C}$ for 68 hours, or to a flowers of sulphur atmosphere at $50^{\circ} \mathrm{C}$ and 75 per cent R.H. for 24 hours. Contact resistance against a solid gold probe was measured as a function of force. It was found that as much as 50 per cent of the base metal could be exposed without significant increase of contact resistance provided the probe was large enough to make electrical contact with gold which remained on the scratched surface. Gold deposits as thin as $0.25 \mu \mathrm{m}$ gave acceptable contact resistance 
behaviour (below $10 \mathrm{~m} \Omega$ ) at forces greater than $60 \mathrm{~g}$. The authors cautioned, however, that these results may not apply to all connectors and engineering evaluations intended to define a satisfactory gold contact finish should be based on conditions which closely resemble the particular application.

\section{Detection of Porosity in Gold Coatings}

F. F. M. Lee and M. Ternowski of International Business Machines, Endicott, New York, proposed a new test for detecting porosity in gold coatings on copper and nickel substrates, which involves exposure of the contacts at $40^{\circ} \mathrm{C}$ in a desiccator to the fumes of 6 per cent sulphurous acid. This test produced equivalent results in one third the time required by a widely used procedure involving exposure to vapours from a dilute sulphuric acid-sodium thiosulphate solution (ASTM, B583-73). A period of exposure of 2 hours is typically used for the quality control of manufactured contacts by the new method. This test can be considered as an alternative to the 2 hours porosity test developed by Clarke and Sansum in 1972 which employs the ASTM reagent at $60^{\circ} \mathrm{C}$.

In an evaluation of the paper electrographic method of determining wear of gold coatings, $M$. Antler and M. H. Drozdowicz of Bell Laboratories, Columbus, Ohio, compared the magnification of decorations in the electrographic print to the sizes of exposed substrate areas in the wear track. The smaller the exposed areas, the more they were found to be magnified, which explains the relatively small range of sizes of pore decorations in the print. Magnification factors varied from 1 for $200 \mu \mathrm{m}$ exposed areas to 20 for $4 \mu \mathrm{m}$ worn spots. The latter was also the lower size limit of detection of exposed base metal substrate with a widely used electrographic procedure.

\section{Accelerated Laboratory Tests}

Several papers described attempts at simulating new environments in laboratory chambers for the evaluation of contact materials and engineering designs of connectors and other components. Work by the West German VDE Technical Committee on 'Contact Behaviour and Switching' was summarized by L. Borchert, U. Mayer, A. Murr, J. Potinecke, and K.-L. Schiff of, respectively Siemens, Doduco, Siemens, Standard Elektrik Lorenz and W. C. Heraeus. Their studies included exposure of pure gold, gold/30 silver, gold/5 nickel and gold/20 silver/10 copper wrought alloys and other materials to an industrial environment at Mannheim and to a variety of laboratory atmospheres. Contact resistances of the exposed materials were determined. The overall result was that pure gold was the least affected material. The order of stability of contact resistance varied with the gold content of the alloy. Gold/5 nickel was nearly as good as the pure metal, being unaffected by an atmosphere of $10 \mathrm{ppm}$ sulphur dioxide and 75 per cent R.H. at $25^{\circ} \mathrm{C}$ after 21 days. After comparable exposure to 1 ppm hydrogen sulphide, the gold-silver alloys showed a ten-fold increase in contact resistance. Atmospheres containing mixtures of the tarnishing agents - hydrogen sulphide, nitrogen dioxide and sulphur dioxide - from fractional to several ppm levels, were more aggressive than were atmospheres containing only one such agent. This seems to be due to an acceleration in the rate of growth of sulphide films on gold alloys containing silver or copper. The authors proposed standard test methods (a): sulphur dioxide $\leq 1$ ppm plus hydrogen sulphide $\leq 0.5 \mathrm{ppm}$; and (b): same as (a) with $\leq 0.5 \mathrm{ppm}$ nitrogen dioxide added. Test conditions would be $25^{\circ} \mathrm{C}$ at 75 per cent R.H. for $1,4,10$ or 21 days, according to the severity of test conditions desired.

K.-L. Schiff and R. Schnable of W. C. Heraeus, Hanau, West Germany, evaluated connectors made of brass blade contacts electroplated with cobalthardened gold on underplatings of nickel or tin/35 per cent nickel alloy that were mated to a copper $/ 6$ per cent nickel spring member clad with gold/24 silver/6 per cent copper or with gold-silver-palladiumindium-tin. Single and mixed gas tests were used, involving ppm levels of hydrogen sulphide or sulphur dioxide, or mixtures of both with or without addition of nitrogen dioxide. Exposures ranged from days to two weeks in a chamber at 75 per cent R.H. and $25^{\circ} \mathrm{C}$. It was found that contact resistances tended to increase if the gold coatings on nickel were thin an porous, for instance, $1 \mu \mathrm{m}$ gold on $2 \mu \mathrm{m}$ of nickel. They also increased with test atmospheres containing hydrogen sulphide in which sulphides crept onto the clad inlay contact surface from exposed copper at the edges of the contacts. However, the resistance of contacts made of $3 \mu \mathrm{m}$ thick gold having little porosity on $2 \mu \mathrm{m}$ of nickel or porous $1 \mu \mathrm{m}$ gold on $2 \mu \mathrm{m}$ of tinnickel alloy electrodeposit was virtually unchanged after 200 cycles of insertion and withdrawal prior to exposure. The good behaviour of thin gold on tinnickel alloy was attributed to the corrosion resistance of the underplate at pores in the gold. Another finding was that the indium-containing alloy showed little edge creep of films from exposed copper, as did binary gold-indium electrodeposits (see above). The authors felt, however, that their tests were too aggressive, since the contact material combination most affected by them ( $1 \mu \mathrm{m}$ gold on $2 \mu \mathrm{m}$ nickel versus gold-silver-copper inlay) was believed to be generally satisfactory in practical applications. Nevertheless, aggressive stress tests can be used to identify connector contact materials likely to succeed in extremely severe environments. 
F. E. Bader, S. P. Sharma, and M. Feder of Bell Laboratories, Columbus, Ohio, proposed a new test in which a real polluted ambient is passed continuously through a laboratory chamber and acceleration is achieved by modification of temperature and R.H. according to an assumed rate equation for corrosion. For connectors intended to serve 40 years in Bell System telephone central offices, an exposure cycle was chosen involving 12 hours each at 80 per cent R.H. and $65^{\circ} \mathrm{C}, 35$ to 40 per cent R.H. and $65^{\circ} \mathrm{C}$ and 35 to 50 per cent R.H. and $25^{\circ} \mathrm{C}$, with a test duration of one year. The chamber was in the basement of a central office in an urban-industrial site. Films on copper and nickel coupons exposed in an air conditioned telephone central office at the same location had similar constituents, morphology and growth kinetics. The acceleration factor in the test was about 100 for copper and nickel. The test was also proposed for gold plated contacts with these materials as substrate. Several different designs of such connectors were examined in the mated condition. It was found that the contact resistance of connectors having good shielding increased slightly and in a well controlled manner, even when the electrodeposited cobalthardened gold on both contacts was thin $(0.75 \mu \mathrm{m})$. Poorly shielded edge connectors with thick gold or gold/30 silver per cent weldments mated to printed circuit boards having electrodeposited gold edge contacts showed distributions of resistance on ageing which became unstable with time for thin $(0.5$ and $1.25 \mu \mathrm{m})$ compared to thick $(2.5 \mu \mathrm{m})$ cobalt-hardened gold deposits. After one year the contact resistance increase was about $10 \mathrm{~m} \Omega$ at the 98 th percentile of a probability distribution plot. Reasons for the contact resistance increases are unknown.

\section{Contamination by Organic Substances}

Additional papers presented at the Conference considered the effect of organic materials on the contact resistance stability of contact materials. Palladium, for example, acquires resistive films under certain conditions in the presence of organic vapours by causing them to form 'static polymer', $M$. Huck of Doduco, Pforzheim, West Germany, studied this phenomenon with the vapours from a variety of plastics used in electrical devices. A $0.2 \mu \mathrm{m}$ thick gold layer electrodeposited on palladium showed a marked ability to attenuate resistance increases. Contact resistance determinations with a solid gold probe at loads of $5 \mathrm{~g}$ were used to monitor film growth.

W. H. Abbott of Battelle Institute, Columbus, Ohio, and W. E. Campbell of Troy, New York, examined 'friction polymer' formation from $500 \mathrm{ppm}$ of benzene vapours during sliding of gold, palladium and platinum contacts under loads of $15 \mathrm{~g}$. Films that developed on palladium were electrically resistive and adherent while those on platinum were non-adherent. Films that developed on high purity gold caused a decrease in the coefficient of sliding friction from more than 1 to 0.3 , lowered the contact resistance by reducing stick-slip motion and diminished the rate of wear. Several coupons of gold-silver and gold-copper alloys gave similar results but cobalt- or nickelhardened gold electrodeposits showed behaviour comparable to that of palladium.

\section{Abrasion and Adhesion Problems}

Other papers presented at the Conference dealt with the behaviour of gold under conditions other than those related to the environment. $M$. Antler and M. H. Drozdowicz of Bell Laboratories, Columbus, Ohio, discussed the adhesive and abrasive wear of electrodeposited gold and the effect of a ductile hard underplate (nickel) and a hard substrate (beryllium copper). Wearing conditions in connector contacts were modelled with rider-on-flat apparatus. It was found that: (a) both the adhesive and abrasive wear of gold deposits could be markedly reduced by hard substrates and underplates, (b) thin film lubrication was effective when adhesive wear predominated but was of little value in abrasive wear, (c) there was a load-dependent minimum thickness of gold coating that did not wear through because of a change in mechanism which occurred during unlubricated sliding in the adhesive regime, (d) sliding under mild conditions, as in the presence of a good boundary lubricant, occurred with lateral flow of gold.which closed as-plated pores and wear-induced breaks produced early in a run, (e) pure (soft) gold coatings were able to resist abrasive wear at loads where hard golds failed by brittle fracture, and ( $f$ ) the prow formation mechanism adequately described the adhesive wear of gold coatings. Nickel underplate may be desirable on connector contacts in order to minimize the wear of gold under high loads or that of thin golds, and in circumstances where it is impractical to use lubricants and where abrasion is the dominant mechanism.

Gold plated nickel-iron is used commercially in the manufacture of reed relays. A common problem has been sticking of the reed blades due to cold welding of clean contacts. Very thin surface oxides can prevent sticking without causing a significant increase in contact resistance because of electron conduction through the oxide by tunnelling. It is common practice to heat-treat gold plated reed blades in an inert atmosphere so as to develop an oxide film. P. Douglas and P. Watson of Plessey Research, Caswell, U.K., considered the kinetics of thermal diffusion of electrodeposited pure and nickel-hardened golds on nickel-iron substrates. Scanning electron microscopy, electron microprobe surface analysis, and examination of transverse microsections of reed blades were 
used to acquire the kinetic information. Diffusion in the gold/nickel-iron system in the temperature range 600 to $950^{\circ} \mathrm{C}$ was found to be by a combined lattice and grain boundary mechanism. Under typical atmospheric conditions, with relatively low moisture contents, the manganese impurity in the substrate segregated and oxidized at the surface of the gold and thus reduced contact sticking. Under similar low moisture conditions, annealing of nickel-iron in the absence of gold did not produce the segregation/depletion phenomenon. In this case, depletion only occurred at much higher moisture contents. A minimum in the failure rate of reed contacts corresponded with a peak in surface manganese content.

In a related contribution, C. A. Haque of Bell Laboratories, Columbus, Ohio, reported upon studies of the diffusion of electroplated layers of gold and silver by Auger spectroscopy and electron spectroscopy for chemical analysis. From 660 to $800^{\circ} \mathrm{C}$, substrate diffusion was minimal, the silver/gold ratio was relatively low and the sticking tendency was high. On heating above about $800^{\circ} \mathrm{C}$, there was considerable diffusion of iron, nickel and manganese from the substrate to the surface, together with an increase in the silver/gold ratio. Base metal oxides which formed decreased the tendency of the surfaces to stick. If oxide thickness (particularly in the case of nickel oxide) became excessive, contact resistance increased, which is another failure mode of reed relays.

T. Dabrowska and W. Francyk of the Technical University of Wroclaw, Poland, compared the contact behaviour of rhodium-against-rhodium reed relay contacts with that of contacts in which one blade was coated with rhodium and the other with gold. Contact resistance and metal transfer were determined during operation. It was found that the gold-against-rhodium configuration was superior to the all-rhodium system. The direction of current flow also affected contact resistance and it was better to make the gold contact positive. Erosion resistance was, however, better when opposite polarity was used.

Fretting corrosion takes place when base metals rub against each other over small amplitudes, of the order of tens of $\mu \mathrm{m}$. Resistive oxide films quickly develop in the wear track. This can occur with electrical components due to differential thermal expansion and contraction of contact members or due to vibration. G. J. Caule and D. Gyuria of Olin Corporation, New Haven, Connecticut, studied this effect with a variety of copper alloys. The most stable material was, as expected, that of their control sample made of electrodeposited gold, $150 \mu \mathrm{m}$ in thickness.

\section{A New Gold-Cadmium Electrodeposit}

R. T. Hill and K. J. Whitlaw of Lea Ronal, U.K. presented the results of a study of a new acid cyanide gold electrodeposit containing one per cent cadmium and one per cent of other elements, identified in their presentation as the components of 'intrinsic polymer'. Deposits had contact resistance stability on heating at $125^{\circ} \mathrm{C}$ for 1000 hours which was superior to that of pure gold. Hardness was 130 to $180 \mathrm{~kg} / \mathrm{mm}^{2}$. Low porosity deposits were readily obtained. The adhesive wear behaviour was comparable to that of a cobalthardened gold. A study of gold-cadmium deposits was published in Gold Bull., 1978, 11, (2), 43-48.

The Proceedings of Contacts/1978 can be obtained from the Dept. of Electrical Engineering, Illinois Institute of Technology, Chicago, I11. 60616, U.S.A.

\section{Gold Electrodeposits Solve an Unusual Wear Problem}

In automatic wrist watches which operate through movement of the wearer's arm, problems may arise due to the rubbing action between the hardened steel spring and its brass housing. If small wear particles of brass detach and enter the watch mechanism they interfere with its running and can even cause complete stoppage.

Since, for technical reasons, changes in the base materials used are not acceptable, an obvious answer to this difficulty was to plate the spring housing with a wear-resistant coating of suitably low coefficient of friction. After numerous trials, the choice for this purpose was a hard gold alloy electrodeposit (GALVATRONIC) developed by Werner Flühmann AG of Duebendorf in Switzerland, and which had for many years been well established as a superior coating for sliprings and contacts of all types (Gold Bulletin, 1976, 9, (1), 11). The alloy composition is $75 \mathrm{gold} / 22$ copper/3 cadmium weight per cent: Electrodeposit hardness is between 380 and $450 \mathrm{HV}$ with a typical tensile strength of $910 \mathrm{MPa}$ and an elongation of 5 per cent. Moreover, it has a single phase unordered structure and a sharp texture with more than $90 \%$ of $\{111\}$ planes parallel to the surface. These features, together with its very small average grain size $(27 \AA)$ and excellent tribological properties make it better suited for the application than a metallurgically prepared 18 carat gold alloy of similar composition.

Hence, the spring housings in a Swiss watch of world-wide repute are currently plated with $1.5 \mu \mathrm{m}$ of this hard gold. This results in an equilibrium between abrasion and repolishing (healing) effects so that over very long periods practically no loose metal is produced by friction between the spring and its housing. 